\title{
Iodine-restricted food versus pharmacological therapy in the management of feline hyperthyroidism: A controlled trial in 34 cats
}

\author{
Giorgio Grossi ${ }^{1}$, Andrea Zoia ${ }^{2}$, Paola Palagiano ${ }^{3}$, Nadia Leoni ${ }^{4}$, Federica Bubini-Regini ${ }^{5}$, Eleonora Malerba ${ }^{1}$, \\ Angelo Peli ${ }^{1}$, Giacomo Biagi ${ }^{1}$ and Federico Fracassi ${ }^{1 *}$ \\ ${ }^{1}$ Department of Veterinary Medical Sciences, University of Bologna, Bologna, Italy \\ ${ }^{2}$ San Marco Veterinary Clinic, Padova, Italy \\ ${ }^{3}$ Meda Veterinary Clinic, Meda, Italy \\ ${ }^{4}$ San Siro Veterinary Clinic, Milano, Italy \\ ${ }^{5}$ Practitioner, Venezia, Italy
}

\begin{abstract}
Background: Hyperthyroidism is a common endocrinopathy of middle-aged and elderly cats. Dietary treatment has been proposed as an alternative to traditional therapies.

Aim: The aim of this prospective study was to compare the efficacy of iodine-restricted food versus pharmacological therapy with methimazole in client-owned cats with hyperthyroidism.

Methods: Indoor cats with newly diagnosed hyperthyroidism (consistent clinical signs and serum total thyroxine concentration greater than $50 \mathrm{nmol} / \mathrm{l}$ ) were assigned to one of three groups: (A) received an iodine-restricted food as a single therapy; (B) received transdermal methimazole in pluronic lecithin organogel; and (C) received oral methimazole. In all groups, clinical parameters, biochemistry, and serum total thyroxine were evaluated at baseline and 10, 30, 60, and 90 days after treatment began.

Results: Thirty-four cats were enrolled in the study (group A: $n=14$; group B: $n=11$; group C: $n=9$ ). No significant differences were found between groups at diagnosis for signalment, clinical and laboratory findings, including serum total thyroxine concentrations. In all the groups, serum total thyroxine concentration decreased significantly following the baseline measurement. After 90 days of treatment, serum creatinine increased significantly only in the methimazoletreated groups. Liver enzyme activities decreased significantly only in group B, while no significant decreases were detected in groups $\mathrm{A}$ and $\mathrm{C}$ at any time.

Conclusion: These results suggest that iodine-restricted food is effective at reducing the total thyroxine concentration in the serum of hyperthyroid cats. Moreover, the iodine-restricted food did not cause any increase in serum creatinine concentrations and failed to improve liver enzymes abnormalities. These findings could indicate a persistent hyperthyroid state in cats treated with iodine-restricted food despite normalization of serum total thyroxine concentrations.

Keywords: Iodine-restricted food, Liver enzymes, Methimazole, Pluronic lecithin organogel, Thyroxine.
\end{abstract}

\section{Introduction}

Hyperthyroidism is one of the most common endocrinopathies in middle-aged and elderly cats. The etiology of the disease remains unclear but several potential risk factors have been described, such as genetic factors and exposure to goitrogenic compounds (McLean et al., 2014). The main clinical signs include weight loss, polyphagia, restlessness, tachycardia, polydipsia/polyuria, vomiting, and diarrhea; furthermore, more than $90 \%$ of hyperthyroid cats have a palpable cervical mass (Broussard et al., 1995; Edinboro et al., 2004; Scott-Moncrieff, 2015). Currently, there are four therapeutic alternatives for feline hyperthyroidism: thyroidectomy, pharmacological therapy (e.g., methimazole and carbimazole), radioiodine therapy, and nutritional therapy. In general, the treatment is chosen based on owner preference and financial resources, the presence of concurrent illnesses, and the possibility of performing surgery or radioiodine therapy (Scott-Moncrieff, 2015). Recently, dietary treatment of feline hyperthyroidism has been proposed. At present, only two studies have been published about the administration of an iodinerestricted food as therapy in client-owned hyperthyroid cats and neither was a controlled study (Van der Kooij et al., 2014; Hui et al., 2015).

The aim of the present study was to evaluate the effects of an iodine-restricted food on clinical and clinicopathological parameters in client-owned cats with hyperthyroidism and to compare the efficacy of dietetic treatment with that of standard pharmacological therapy with oral and transdermal methimazole.

\section{Materials and Methods}

The present study was designed as a prospective, multi-center, non-randomized controlled trial. The 
experimental protocol was approved by the Scientific Ethics Committee of the University of Bologna. Written informed consent was obtained from each owner before enrollment in the study.

\section{Animal selection}

Client-owned cats with newly diagnosed, naturally occurring hyperthyroidism were enrolled in the study. The trial was performed from November 2012 to March 2016 at a University Department and in private veterinary clinics.

Cats were included in the study if they had consistent clinical signs compatible with hyperthyroidism and a serum total thyroxine $\left(\mathrm{TT}_{4}\right)$ concentration greater than $50 \mathrm{nmol} / \mathrm{L}$ (reference interval for the laboratory: $15-42$ $\mathrm{nmol} / \mathrm{l})$.

Cats that had previously been treated for hyperthyroidism, cats with severe concurrent disorders [i.e., lymphoma, other neoplasms, malabsorption, severe azotemia (IRIS > 2)] and cats that lived outdoors were excluded from the study.

Based on owner needs and preference, cats were allocated into three groups. Group A received an iodinerestricted diet (Hill's Prescription Diet-y/d Feline Thyroid Health) as the only therapy. The owners were instructed to administer the iodine-restricted food as the only diet, avoiding any other type of food (including snacks). For this reason, if other cohabiting animals were receiving a different food or the administration of the sole iodine-restricted food was not possible, the nutritional therapy was not recommended as the first choice. Cats could be fed with dry food, canned food, or both. The transition to the new diet had to take place within 3-4 days (during this period, the iodinerestricted food was mixed with the previous food). Group B received transdermal methimazole in pluronic lecithin organogel. It was produced by a single pharmacy in $2.5 \mathrm{ml}$ syringes, at the concentration of $25 \mathrm{mg} / \mathrm{ml}$. Transdermal methimazole was applied to the cat's inner pinna, alternating ears with each administration, at the starting dose of $2.5 \mathrm{mg} \mathrm{q} 12 \mathrm{~h}$. Owners wore latex gloves during administration and were instructed to remove crusted material before the next dose was given.

Group C received oral methimazole (Tapazole, Teofarma; Felimazole, Dechra) at the starting dose of $2.5 \mathrm{mg} / \mathrm{cat} \mathrm{q} 12 \mathrm{~h}$.

\section{Diagnosis and follow-up}

At diagnosis, the main medical history, body weight, and data from the physical examination were recorded for each cat. The definitive diagnosis and exclusion of severe comorbidities were based on laboratory tests: complete blood count, serum biochemistry profile, and serum $\mathrm{TT}_{4}$ concentration. If indicated (e.g., heart murmur, palpable abdominal mass, pulmonary sounds alterations), other diagnostic investigations were performed (i.e., urinalysis, thoracic radiographs, abdominal ultrasonography, echocardiography) to rule out concurrent severe disorders.
Cats were evaluated at $10 \pm 2(\mathrm{~T} 10), 30 \pm 5$ (T30), $60 \pm$ 10 (T60), and $90 \pm 10$ (T90) days after treatment began. At those time points, anamnesis, physical examination, serum creatinine, urea, alanine transaminase (ALT), aspartate transaminase (AST), alkaline phosphatase (ALP), and $\mathrm{TT}_{4}$ concentrations were assessed. The goals of therapy were to achieve resolution of the clinical signs of hyperthyroidism and a serum $\mathrm{TT}_{4}$ concentration within the reference interval. In groups $\mathrm{B}$ and $\mathrm{C}$, after the re-evaluations, the dosage of methimazole was increased or decreased by 1.25-2.5 $\mathrm{mg} / \mathrm{cat} \mathrm{q} 12-24 \mathrm{~h}$ if indicated.

A chemiluminescent enzyme immunoassay (Immulite) was used to measure serum $\mathrm{TT}_{4}$ concentrations in all cats. Serum biochemical profiles were performed using standard laboratory methods (Biochemistry AU2700 Beckman-Coulter/Olympus, O'Callaghan's Mills, Ireland).

\section{Statistical analysis}

At diagnosis, differences between the three groups were evaluated using Fisher's exact test for categorical data (breed and sex). The differences between groups regarding continuous data (age, body weight, $\mathrm{TT}_{4}$, serum creatinine, urea, ALT, AST, and ALP) at the same time of treatment were evaluated by Kruskal-Wallis test followed by the Mann-Whitney test. KruskalWallis test with post hoc analysis (Dunn's Multiple Comparison Test) was used to evaluate the withingroup differences at different times (i.e., T0-T90). Data were analyzed using a commercially available software program (GraphPad Prism 5, Graphpad Software Inc., San Diego, CA). Statistical significance was set at $p<0.05$.

\section{Results}

\section{Clinical findings}

Thirty-four cats were included in the study. Thirtythree cats were Domestic Short-Hairs and one was a Persian cat. The median age at diagnosis was 14 years (range of 8-18 years). Nineteen cats were female (14 neutered) and 15 were male (14 neutered). Clinical signs reported by owners included weight loss $(25 / 34$, $74 \%$ ), vomiting $(19 / 34,56 \%)$, polyphagia $(18 / 34$, $53 \%$ ), polydipsia/polyuria $(12 / 34,35 \%)$, dyspnea $(11 / 34,32 \%)$, skin changes $(10 / 34,29 \%)$, restlessness $(6 / 34,18 \%)$, diarrhea $(6 / 34,18 \%)$, and lethargy $(2 / 34$, $6 \%$ ). Furthermore, at physical examination, 29/34 $(85 \%)$ cats had a palpable thyroid and $11 / 34$ (32\%) cats had a heart murmur.

\section{Groups}

At diagnosis, all three groups were homogeneous for the breed, sex, age, body weight, $\mathrm{TT}_{4}$, and biochemical parameters (serum creatinine, urea, ALT, AST, and SAP) (Table 1).

Fourteen cats were included in group A (10 females and 4 males). At diagnosis (T0), one cat was immediately excluded because of food refusal, and, therefore, 
Table 1. Clinical and clinicopathological parameters in hyperthyroid cats treated for a 3 months period with iodine-restricted food, transdermal methimazole, or oral methimazole.

\begin{tabular}{|c|c|c|c|}
\hline Variable & $\begin{array}{l}\text { Group A: Iodine- } \\
\text { restricted food }\end{array}$ & $\begin{array}{c}\text { Group B: Transdermal } \\
\text { methimazole }\end{array}$ & $\begin{array}{l}\text { Group C: Oral } \\
\text { methimazole }\end{array}$ \\
\hline \multicolumn{4}{|l|}{ Baseline data (T0) } \\
\hline No. of cats & 13 & 11 & 9 \\
\hline Body weight (kg) & $3.3(2.0-5.3)$ & $3.8(1.9-4.3)$ & $3.5(2.5-5.4)$ \\
\hline $\mathrm{TT}_{4}(\mathrm{nmol} / \mathrm{l})(\mathrm{RI}: 15-42)$ & $156(98-309)$ & $225(89-309)$ & $142(58-309)$ \\
\hline Creatinine (mol/1) (RI:70-159) & $93(55-163)$ & $96(69-150)$ & $102(84-143)$ \\
\hline Urea (mmol/l) (RI:10.7-23.2) & $20.1(15.9-37.9)$ & $23.6(12.9-37.0)$ & $21.4(12.9-31.2)$ \\
\hline ALT (U/1) (RI:22-45) & $164(27-708)$ & $185(48-1130)$ & $110(58-591)$ \\
\hline AST (U/1) (RI:14-41) & $54(23-228)$ & $65(25-141)$ & $49(26-186)$ \\
\hline ALP (U/1) (RI:0-120) & $285(41-537)$ & $182.5(25-420)$ & $83(45-447)$ \\
\hline \multicolumn{4}{|l|}{ After 10 days (T10) } \\
\hline No. of cats & 10 & 9 & 9 \\
\hline Body weight (kg) & $3.4(1.8-5.9)$ & $4.1(2.7-4.8)$ & $3.6(2.6-5.8)$ \\
\hline $\mathrm{TT}_{4}(\mathrm{nmol} / \mathrm{l})(\mathrm{RI}: 15-42)$ & $86(28-114) *$ & $69(5-157) *$ & $27(5-118) *$ \\
\hline Creatinine $(\mu \mathrm{mol} / \mathrm{l})(\mathrm{RI}: 70-159)$ & $89(58-164)$ & $119(96-195)$ & $123(94-184)$ \\
\hline Urea (mmol/1) (RI:10.7-23.2) & $16.3(14.8-30.5)$ & $24.3(18.1-42.8)$ & $26.3(18.4-36.6)$ \\
\hline ALT (U/1) (RI:22-45) & $203(38-740)$ & $160(72-655)$ & $92(50-176)$ \\
\hline AST (U/1) (RI:14-41) & $76(26-131)$ & $43(36-487)$ & $44(26-62)$ \\
\hline $\operatorname{ALP}(\mathrm{U} / \mathrm{L})(\mathrm{RI}: 0-120)$ & $241(77-679)$ & $144(80-236)$ & $120(26-248)$ \\
\hline \multicolumn{4}{|l|}{ After 30 days (T30) } \\
\hline No. of cats & 10 & 10 & 9 \\
\hline Body weight (kg) & $3.3(2.1-5.9)$ & $4.1(2.8-4.5)$ & $3.6(2.9-6.2)$ \\
\hline $\mathrm{TT}_{4}(\mathrm{nmol} / \mathrm{l})(\mathrm{RI}: 15-42)$ & $70(19-151) *$ & $79(6-290) *$ & $14(5-70) *$ \\
\hline Creatinine $(\mu \mathrm{mol} / \mathrm{l})(\mathrm{RI}: 70-159)$ & $95(42-169)$ & $130(67-227)$ & $143(103-201) *$ \\
\hline Urea (mmol/1) (RI:10.7-23.2) & $19.2(14.3-31.5)$ & $22.1(15.6-30.6)$ & $26.8(18.8-34.6)$ \\
\hline ALT (U/1) (RI:22-45) & $158(41-711)$ & $145(55-560)$ & $63(36-141) \bullet$ \\
\hline AST (U/1) (RI:14-41) & $58(28-195)$ & $55(23-93)$ & $39(21-63)$ \\
\hline $\operatorname{ALP}(\mathrm{U} / \mathrm{l})(\mathrm{RI}: 0-120)$ & $207(83-826)$ & $107(44-177)$ & $96(14-209)$ \\
\hline \multicolumn{4}{|l|}{ After 60 days (T60) } \\
\hline No. of cats & 8 & 9 & 8 \\
\hline Body weight (kg) & $3.3(2.3-6.3)$ & $4.3(3.1-5.0)$ & $3.7(2.9-6.1)$ \\
\hline $\mathrm{TT}_{4}(\mathrm{nmol} / \mathrm{L})(\mathrm{RI}: 15-42)$ & $61(19-152) *$ & $42(13-175) *$ & $18(5-86) *$ \\
\hline Creatinine $(\mu \mathrm{mol} / \mathrm{l})(\mathrm{RI}: 70-159)$ & $97(35-187)$ & $135(90-196)$ & $150(118-255) *$ \\
\hline Urea (mmol/l) (RI:10.7-23.2) & $19.5(16.0-40.1)$ & $26.5(18.5-31.7)$ & $25.8(22.8-54.3)$ \\
\hline ALT (U/1) (RI:22-45) & $195(34-475)$ & $80(61-163)$ & $67(37-250)$ \\
\hline AST (U/1) (RI:14-41) & $63(32-186)$ & $35(23-90) *$ & $40(19-88)$ \\
\hline ALP (U/1) (RI:0-120) & $157(91-293)$ & $91(55-187)$ & $95(18-161)$ \\
\hline \multicolumn{4}{|l|}{ After 90 days (T90) } \\
\hline No. of cats & 6 & 9 & 8 \\
\hline Body weight (kg) & $3.8(3.0-6.1)$ & $4.2(3.4-5.3)$ & $4.1(2.8-6.2)$ \\
\hline $\mathrm{TT}_{4}(\mathrm{nmol} / \mathrm{l})(\mathrm{RI}: 15-42)$ & $36(18-55) *$ & $19(5-73) *$ & $20(5-72) *$ \\
\hline
\end{tabular}




\begin{tabular}{lccc}
\hline Variable & $\begin{array}{c}\text { Group A: Iodine- } \\
\text { restricted food }\end{array}$ & $\begin{array}{c}\text { Group B: Transdermal } \\
\text { methimazole }\end{array}$ & $\begin{array}{c}\text { Group C: Oral } \\
\text { methimazole }\end{array}$ \\
\hline Creatinine $(\mu \mathrm{mol} / \mathrm{l})(\mathrm{RI}: 70-159)$ & $94(39-210)$ & $147(124-202) *$ & $163(124-316) *$ \\
\hline Urea $(\mathrm{mmol} / \mathrm{l})(\mathrm{RI}: 10.7-23.2)$ & $20.0(14.5-24.5)$ & $25.8(17.8-34.3)$ & $28.2(20.7-55.6)$ \\
ALT $(\mathrm{U} / \mathrm{l})(\mathrm{RI}: 22-45)$ & $154(62-460)$ & $79(47-127) *$ & $61(20-310)$ \\
AST $(\mathrm{U} / \mathrm{l})(\mathrm{RI}: 14-41)$ & $45(28-174)$ & $27(23-42) *$ & $44(15-131)$ \\
ALP $(\mathrm{U} / \mathrm{l})(\mathrm{RI}: 0-120)$ & $146(82-267)$ & $(29-121) *$ & $79(7-202)$ \\
\hline
\end{tabular}

ALT, alanine transaminase; AST, aspartate transaminase; ALP, alkaline phosphatase; $\mathrm{TT}_{4}$ total thyroxin. Data are given as median (range). RI: reference interval for healthy cats. *Significantly different $(p<0.05)$ from baseline (T0) for that treatment group; Significantly different $(p$ $<0.05)$ from the iodine restricted food treatment group at the time point; $\bullet$ Significantly different $(p<0.05)$ from the transdermal methimazole treatment group at the time point.

was also excluded from the statistical analysis. After T30, another four cats were excluded from the study: two for food refusal, one for poor owner compliance regarding food administration, and the last one for loss to follow-up. After T60, another cat was excluded due to food refusal and one died due to suspected aortic thromboembolism. Another cat missed the last followup (T90).

Eleven cats were included in group B (4 females and 7 males). After T10, one cat left the study due to suspected methimazole-induced hepatotoxicity, with the deterioration of coat hair, dehydration, and increased liver transaminases. Another cat developed an excoriation at the site of application of transdermal methimazole after T10, which was resolved by dividing the dose between the two ears, allowing this cat to complete the study. Finally, one cat missed the last follow-up (T90).

Nine cats were included in group C (5 females and 4 males) and only one cat missed the last follow-up (T90). Each group contained cats that did not attend all followup appointments because of poor owner compliance. Table 1 shows the number of cats included for statistical analysis in the three groups for each time point.

\section{Bodyweight}

Throughout the trial, no significant differences were found in all groups between $\mathrm{T} 0$ and all other time points (group A: $p=0.5454$; group $\mathrm{B}: p=0.2853$; group $\mathrm{C}$ : $p=0.4896$ ) (Table 1). Moreover, no differences were found among the three experimental groups at the same time point (Table 1).

\section{Laboratory findings}

In all the groups, $\mathrm{TT}_{4}$ concentration decreased significantly from $\mathrm{T} 0$ to the other time points (Fig. 1) and no differences were found among the three groups at T90 ( $p=0.5177)$ (Table 1$)$. At the end of the study, $3 / 6$ cats $(50 \%)$ in group A, 5/9 (56\%) in group B, and $7 / 8(88 \%)$ in group $\mathrm{C}$ had $\mathrm{TT}_{4}$ concentrations below $42 \mathrm{nmol} / \mathrm{l}$ (Table 2) and the median $\mathrm{TT}_{4}$ concentration was in the reference interval in all groups (Table 1). However, only methimazole groups had median $\mathrm{TT}_{4}$ values in the lower half of the reference interval. During the various follow-up periods, 10/37 cases $(27 \%)$ in group B and $14 / 33$ cases $(42 \%)$ in group C had a serum $\mathrm{TT}_{4}$ lower than $15 \mathrm{nmol} / \mathrm{L}$ (Table 2), but none of these cats showed clinical signs of iatrogenic hypothyroidism. $\mathrm{TT}_{4}$ values lower than $15 \mathrm{nmol} / \mathrm{l}$ were not detected in cats in group A (Table 2).

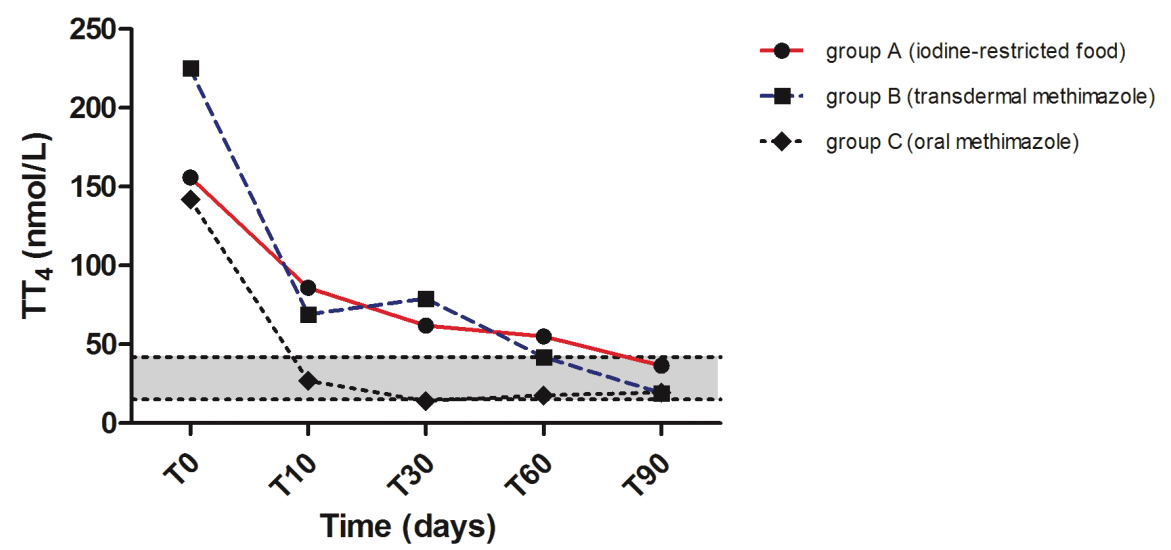

Fig. 1. Median values of serum total thyroxine $\left(\mathrm{TT}_{4}\right)$ before and during treatment with iodinerestricted food, transdermal methimazole, and oral methimazole. The gray area represents the reference interval for total thyroxine. 


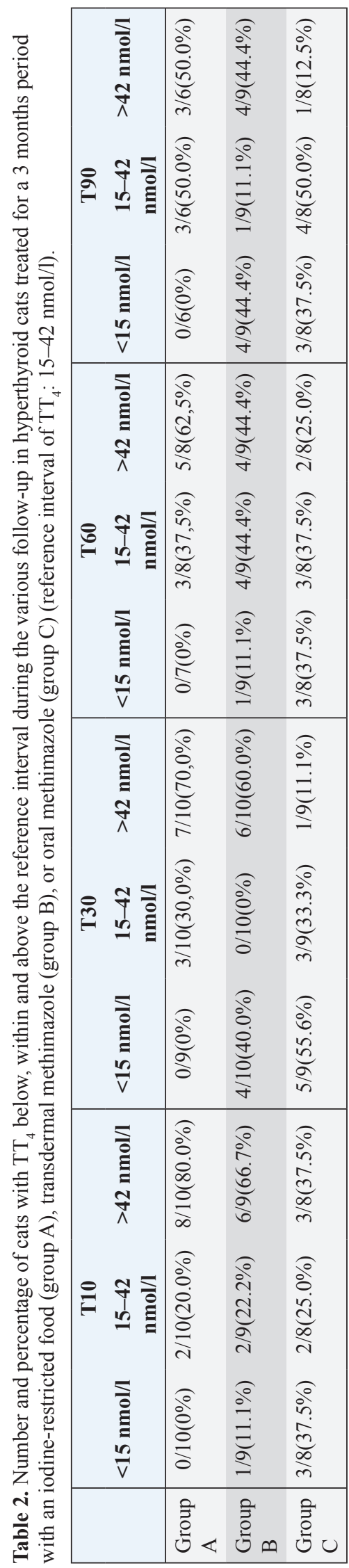

Serum creatinine increased significantly between $\mathrm{T} 0$ T90 ( $p=0.0123)$ in group B and between T0-30, T0$\mathrm{T} 60$, and $\mathrm{T} 0-\mathrm{T} 90(p=0.0013)$ in group $\mathrm{C}$, while no significant change was detected in group A (Fig. 2). Moreover, serum creatinine was significantly higher in group C compared with group A at T30 $(p=0.0142)$ and T60 ( $p=0.0149)$ (Table 1).

No significant variations in urea were found within any of the groups during the study. However, urea was significantly higher in groups $\mathrm{B}$ and $\mathrm{C}$ compared to group A at T10 ( $p=0.0279$, in both cases $)$ and T90 ( $p=$ 0.0256 and $p=0.0127$, respectively) (Table 1 ).

During the study, ALT decreased significantly in group B from T0 to T90 $(p=0.0078)$, while no significant decrease was detected in groups $\mathrm{A}$ and $\mathrm{C}$ over time (Fig. $3)$. Likewise, AST decreased significantly in group B from T0 to T60 and T90 $(p<0.0001)$ but not in groups $\mathrm{A}$ and $\mathrm{C}$ (Table 1). Despite these results, no significant differences were found among the three groups at T90 regarding ALT $(p=0.0935)$ and AST $(p=0.0673)$.

ALP decreased significantly from T0 to T90 $(p=$ 0.0015 ) in group B, but not in the other groups (Fig. 4). Moreover, ALP was significantly lower in groups $\mathrm{B}$ and $\mathrm{C}$, compared to group A, at T30 $(p=0.0057$ and $p=0.0244$, respectively $)$ and at T60 $(p=0.0228$ and $p=0.0371$, respectively), while at T90 only group B preserved this difference with group A $(p=0.0048)$ (Table 1).

\section{Discussion}

Results from the present study suggest that both iodinerestricted food and methimazole (oral and transdermal) are effective in reducing the serum $\mathrm{TT}_{4}$ concentration in hyperthyroid cats. However, at the end of the study, some cats in groups A (50\%) and B (44\%) and only one $(11 \%)$ in group $\mathrm{C}$ had still a $\mathrm{TT}_{4}$ over the reference interval and they were considered to have mild hyperthyroidism. Guidelines for the treatment of feline hyperthyroidism suggest a $\mathrm{TT}_{4}$ in the lower half of the reference interval as the treatment goal (Daminet et al., 2014). Although this was not a primary goal of the present study, only median $\mathrm{TT}_{4}$ concentrations of methimazole groups have reached this objective after 3 months of treatment.

Until now, there are only two published studies regarding the use of iodine-restricted food in clientowned hyperthyroid cats (Van der Kooij et al., 2014; Hui et al., 2015). Our results on the ability of the iodinerestricted food to normalize the $\mathrm{TT}_{4}$ concentration (37.5\% of cats with serum $\mathrm{TT}_{4}$ concentration within reference range 60 days after starting treatment) were similar to those observed by Hui et al. (2015) (42\% of cats with serum $\mathrm{TT}_{4}$ concentration within reference range 21-60 days after starting treatment) but lower than those reported by van der Kooij et al. (2014) (75\% of cats with serum $\mathrm{TT}_{4}$ concentration within reference range after 8 weeks). 


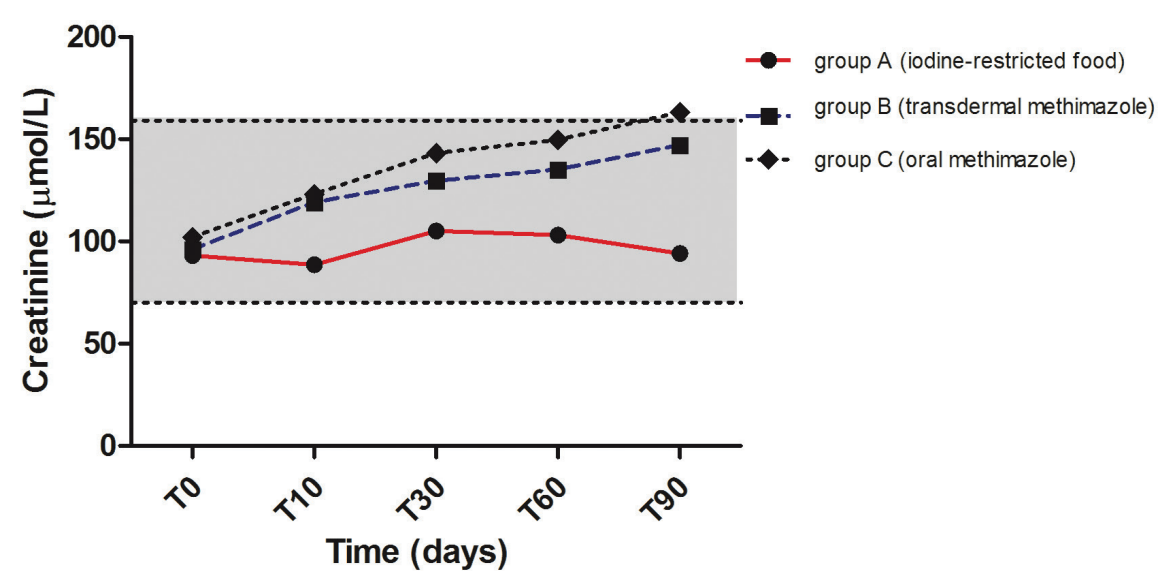

Fig. 2. Median values of serum creatinine before and during treatment with iodine-restricted food, transdermal methimazole, and oral methimazole. The gray area represents the reference interval for serum creatinine.

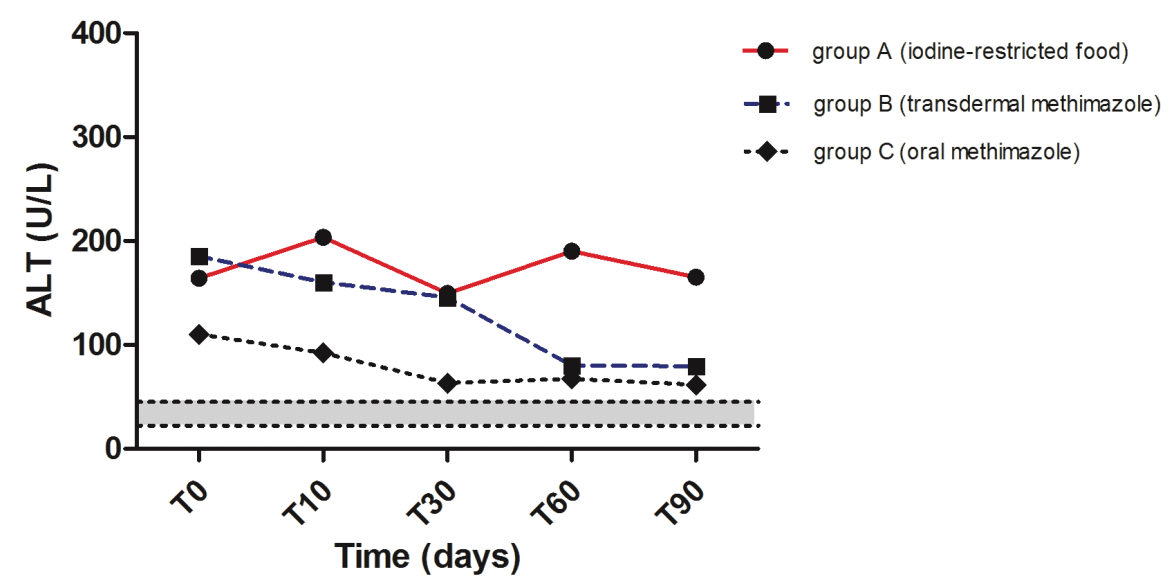

Fig. 3. Median values of ALT before and during treatment with iodine-restricted food, transdermal methimazole, and oral methimazole. The gray area represents the reference interval for alanine transaminase.

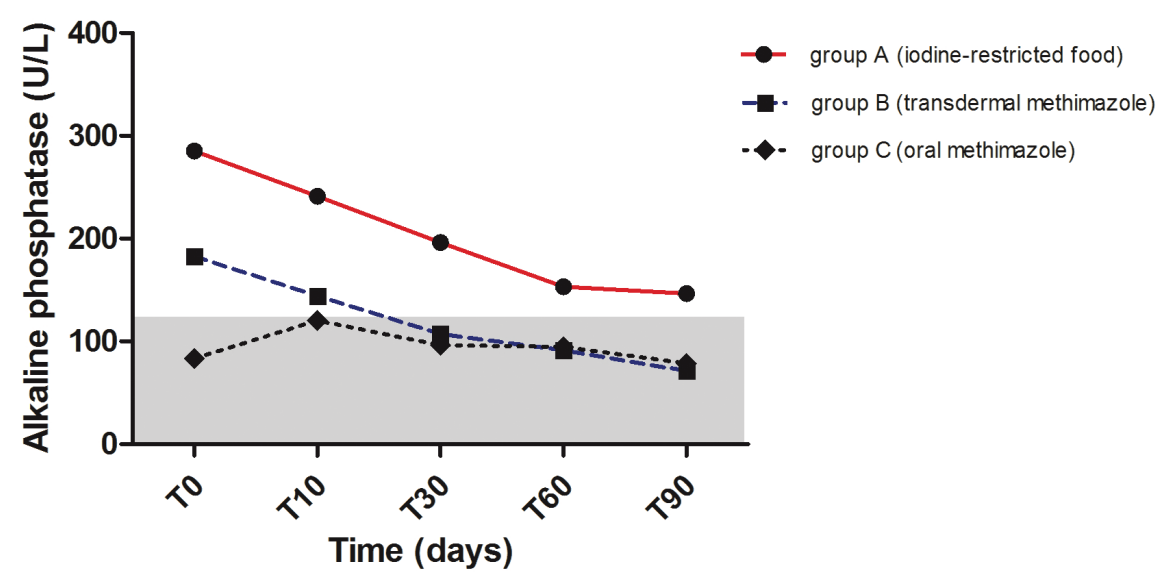

Fig. 4. Median values of alkaline phosphatase before and during treatment with iodinerestricted food, transdermal methimazole, and oral methimazole. The gray area represents the reference interval for alkaline phosphatase. 
Several papers have been published about the use of transdermal methimazole in hyperthyroid cats (Hoffmann et al., 2003; Sartor et al., 2004; Lécuyer et al., 2006; Boretti et al., 2014). In these studies, a higher percentage of cats became euthyroid within the timescale considered in the present study. However, transdermal methimazole is a galenic preparation and there may be mild differences in formulation and bioavailability of the active principle among studies. In the only study where oral and transdermal methimazole were compared, the oral formulation resulted in a more rapid resolution of hyperthyroidism (Sartor et al., 2004). Likewise, in our study, after 10 days of treatment, despite no significant difference were found between groups, the percentage of hyperthyroid cats was markedly lower in the group treated with oral methimazole, compared with the group treated with transdermal methimazole. The lack of statistical significance is possibly due to the low number of cats included.

One possible complication of the treatment of hyperthyroidism is the development of iatrogenic hypothyroidism. This condition should be avoided in cats because it appears to contribute to the development of azotemia (Williams et al., 2010). In the present trial, some of the cats treated with oral and transdermal methimazole had $\mathrm{TT}_{4}$ values below $15 \mathrm{nmol} / \mathrm{L}$ during the treatment period, but none of these cats showed any clinical signs of hypothyroidism. This is probably due to the frequent re-evaluations and adjustments of the dose. Furthermore, a low $\mathrm{TT}_{4}$ concentration does not necessarily equate with a diagnosis of hypothyroidism and for this reason, thyroid-stimulating hormone (TSH) should also be evaluated (Daminet et al., 2014). None of the cats treated with iodine-restricted food had levels of $\mathrm{TT}_{4}$ below $15 \mathrm{nmol} / \mathrm{l}$.

In previous studies on the use of methimazole in hyperthyroid cats, no significant variations were found in body weight after treatment began (Trepanier et al., 2003; Sartor et al., 2004). Nevertheless, in the only long-term follow-up study performed with hyperthyroid cats, an initial weight gain has been described (Boretti et al., 2014). The lack of increase in body weight is also reported in cats treated with iodine-restricted food (Hui et al., 2015). In our study, despite the lowering of serum $\mathrm{TT}_{4}$ in all groups, no significant variations were found in body weight. It is possible that these data are influenced by the low number of cats included and by the short-term follow-up.

In our study, $29 \%$ of cats refused the diet at different times. This could be the consequence of poor palatability of this food, which compromises the long-term effectiveness of the nutritional treatment. Particularly, cats could initially accept the diet because of polyphagia induced by hyperthyroidism, but it could be later refused when serum $\mathrm{TT}_{4}$ decreases at lower concentrations and the clinical picture improves.
It has been observed that treatment of feline hyperthyroidism with methimazole results in a decrease in glomerular filtration rate and an increase in serum creatinine concentrations (Graves et al., 1994; Becker et al., 2000). On the contrary, the authors of both previous studies on the treatment of feline hyperthyroidism with an iodine-restricted food reported no changes in serum creatinine concentrations (Van der Kooij et al., 2014; Hui et al., 2015). Our study confirms these data. In fact, serum creatinine increased in both the transdermal and oral methimazole groups, but not in the iodine-restricted food group. The lack of increase in serum creatinine in cats treated with iodine-restricted food could be related to a state of incomplete remission of hyperthyroidism despite the normalization of serum $\mathrm{TT}_{4}$. In humans, low levels of TSH and normal thyroid hormone concentrations are indicative of "subclinical hyperthyroidism" (Donangelo and Braunstein, 2011). Unfortunately, a condition of "subclinical hyperthyroidism" has never been described in cats and we did not measure TSH. Another explanation may involve the possible protective effect of diet on the kidney: in fact, the iodine-restricted food is characterized by a high content of omega-3 fatty acids and a moderate protein content (Van der Kooij et al., 2014; Hui et al., 2015). Again, $\mathrm{TT}_{4}$ did not fall below the reference interval in any of the cats treated with iodine-restricted food in this study and this could have prevented azotemia induced by iatrogenic hypothyroidism. Finally, resolution of hyperthyroidism should improve muscle mass and then an increase of creatinine is expected also for this reason. In our study, no statistically significant variations in body weight were observed during all treatments; however, we did not evaluate Muscle Condition Score (MCS). For this reason, we cannot exclude that a poor improvement of MCS in cats treated with iodine-restricted food may have influenced creatinine.

Hyperthyroidism often causes an increase in liver enzyme concentrations. It has been observed that liver enzyme activity tends to decrease after medical therapy with methimazole (Sartor et al., 2004; Chapman et al, 2005). In our study, liver enzyme activity (ALT, AST, and ALP) decreased significantly after 90 days only in cats treated with transdermal methimazole. However, the data on cats treated with oral methimazole were probably influenced by the small number of animals included in this group; in fact, liver enzyme activity tended to decrease in cats treated with oral methimazole, although not significantly. To our knowledge, there are no data in the literature regarding changes in the activity of liver enzymes in hyperthyroid cats fed an iodine-restricted food. In our study, the activity of liver enzymes was not improved under the nutritional therapeutic approach. In this case, the lack of decrease in liver enzyme activity could be related to the incomplete resolution of hyperthyroidism despite normalization of serum $\mathrm{TT}_{4}$, or, again, to the 
small number of cats included in this group. Another possibility is that more time may be needed for liver enzyme activity to respond to dietary treatment.

Several adverse effects have been reported following the utilization of methimazole in hyperthyroid cats (Daminet et al., 2014). In a controlled trial aimed at comparing oral with transdermal methimazole, there was a significant reduction in the development of gastrointestinal adverse effects in cats treated via the transdermal route (Sartor et al., 2004). In our study, two cats developed adverse effects with transdermal methimazole: one cat developed a marked increase in transaminases and, therefore, the methimazole was discontinued; another cat developed a dermatological reaction at the site of administration of transdermal methimazole; this problem was solved by splitting each dose between the two ears. However, no adverse effects were observed in cats treated with oral methimazole or iodine-restricted food. One cat treated with iodine-restricted food died due to suspect aortic thromboembolism. In the last follow-up (T60), this cat had a serum $\mathrm{TT}_{4}$ concentration of $95 \mathrm{nmol} / \mathrm{l}$; for this reason, a correlation between this event and the lack of control of hyperthyroidism cannot be excluded.

This study represents the first controlled trial comparing medical therapy and iodine-restricted food in the management of hyperthyroidism in client-owned cats. Furthermore, we decided to use more restrictive inclusion criteria than those used in previous studies on iodine-restricted food (Van der Kooij et al., 2014; Hui et al., 2015). In fact, we only included indoor cats with no severe comorbidities. Finally, the same analytical method was used to measure serum $\mathrm{TT}_{4}$ concentrations and the biochemistry parameters in all samples and this is a major advantage of this study.

The main limitation of this study is the small number of cats included in each group and this likely influenced the lack of significance of some of the comparisons. Moreover, several cats dropped out of the study for various reasons and only a limited number of subjects concluded the trial. Another limitation is represented by the duration of the study (3 months), which may have been too short to evaluate the long-term effects of the iodine-restricted food in comparison to medical treatment, both in terms of efficacy and side effects. In fact, there has been one previous study on the use of an iodine-restricted diet in euthyroid cats for 1 year (Wedekind et al., 2010), but no data are available about the long-term use of an iodine-restricted diet in hyperthyroid cats.

Another limitation of the present study was the lack of randomization of the treatments, which was not possible because some cats had access to other food sources (e.g., for other cohabiting animals), in which case methimazole was assigned as the treatment option. Moreover, in many cases, the treatment option was based on the owner's preferences.

In conclusion, both iodine-restricted food and methimazole (oral and transdermal) seem to be effective at reducing the serum $\mathrm{TT}_{4}$ concentration in hyperthyroid cats. However, in our study, about $30 \%$ of cats refused the diet, presumably due to poor palatability; this could, therefore, influence the long-term effectiveness of this treatment. The iodine-restricted food did not result in increased serum creatinine concentrations and did not reduce levels of liver enzymes compared with cats treated with methimazole. Further studies are needed to assess whether these findings are indicative of a persistent hyperthyroid state despite the normalization of serum $\mathrm{TT}_{4}$.

\section{Conflict of interest}

Dr Fracassi has previously lectured at meetings for practitioners commissioned by Hill's, the company that produces and sells $y / d$. However, Hill's was not involved in the present study in any way.

\section{References}

Becker, T.J., Graves, T.K., Kruger, J.M., Braselton, W.E. and Nachreiner, R.F. 2000. Effects of methimazole on renal function in cats with hyperthyroidism. J. Am. Anim. Hosp. Assoc. 36, 215-223.

Boretti, F.S., Sieber-Ruckstuhl, N.S., Schäfer, S., Gerber, B., Baumgartner, C., Riond, B., HofmannLehmann, R. and Reusch, C.E. 2014. Transdermal application of methimazole in hyperthyroid cats: a long-term follow-up study. J. Feline Med. Surg. 16, 453-459.

Broussard, J.D., Peterson, M.E. and Fox, P.R. 1995. Changes in clinical and laboratory findings in cats with hyperthyroidism from 1983 to 1993. J. Am. Vet. Med. Assoc. 206, 302-305.

Chapman, E., Johnston, L. and Graham, P. 2005. Treatment of feline hyperthyroidism with $2.5 \mathrm{mg}$ thiamazole (methimazole): efficacy and safety. In Proceedings of 15th ECVIM-CA Congress, Glasgow, United Kingdom, pp: 218-219.

Daminet, S., Kooistra, H.S., Fracassi, F., Graham, P.A., Hibbert, A., Lloret, A., Money, C.T., Neiger, R., Rosenberg, D., Syme, H.M., Villard, I. and Williams, G. 2014. Best practice for the pharmacological management of hyperthyroid cats with antithyroid drugs. J. Small Anim. Pract. 55, 4-13.

Donangelo, I. and Braunstein, G.D. 2011. Update on subclinical hyperthyroidism. Am. Fam. Physician 83, 933-938.

Edinboro, C.H., Scott-Moncrieff, J.C., Janovitz, E., Thacker, H.L. and Glickman, L.T. 2004. Epidemiologic study of relationships between consumption of commercial canned food and risk of hyperthyroidism in cats. J. Am. Vet. Med. Assoc. 224, 879-886.

Graves, T.K., Olivier, N.B., Nachreiner, R.F., Kruger, J.M., Walshaw, R. and Stickle, R.L. 1994. Changes in renal function associated with treatment of hyperthyroidism in cats. Am. J. Vet. Res. 55, 17451749.

Hoffmann, G., Marks, S.L., Taboada, J., Hosgood, G.L. and Wolfsheimer, K.J. 2003. Transdermal 
methimazole treatment in cats with hyperthyroidism. J. Feline Med. Surg. 5, 77-82.

Hui, T.Y., Bruyette, D.S., Moore, G.E. and ScottMoncrieff, J.C. 2015. Effect of feeding an iodine-restricted diet in cats with spontaneous hyperthyroidism. J. Vet. Intern. Med. 29, 10631068.

Lécuyer, M., Prini, S., Dunn, M.E. and Doucet, M.Y. 2006. Clinical efficacy and safety of transdermal methimazole in the treatment of feline hyperthyroidism. Can. Vet. J. 47, 131-135.

McLean, J.L., Lobetti, R.G. and Schoeman, J.P. 2014. Worldwide prevalence and risk factors for feline hyperthyroidism: a review. J. S. Afr. Vet. Assoc. 85(1), 1097.

Sartor, L.L., Trepanier, L.A., Kroll, M.M., Rodan, I. and Challoner, L. 2004. Efficacy and safety of transdermal methimazole in the treatment of cats with hyperthyroidism. J. Vet. Intern. Med. 18, 651655.

Scott-Moncrieff, J.C. 2015. Hyperthyroidism. In Canine and Feline Endocrinology, 4th ed. Eds.,
Feldman, E.C., Nelson, R.W., Reusch, C.E., ScottMoncrieff. St. Louis, MO: Elsevier Inc, pp: 136195.

Trepanier, L.A., Hoffman, S.B., Kroll, M., Rodan, I. and Challoner, L. 2003. Efficacy and safety of once versus twice daily administration of methimazole in cats with hyperthyroidism. J. Am. Vet. Med. Assoc. 222, 954-958.

Van der Kooij, M., Bečvářová, I., Meyer, H.P., Teske, E. and Kooistra, H.S. 2014. Effects of an iodine-restricted food on client-owned cats with hyperthyroidism. J. Feline Med. Surg. 16, 491-498.

Wedekind, K.J., Blumer, M.E., Huntington, C.E., Spate, V. and Morris, J.S. 2010. The feline iodine requirement is lower than the $2006 \mathrm{NRC}$ recommended allowance. J. Anim. Physiol. Anim. Nutr. 94, 527-539.

Williams, T.L., Elliott, J. and Syme, H.M. 2010. Association of iatrogenic hypothyroidism with azotemia and reduced survival time in cats treated for hyperthyroidism. J. Vet. Intern. Med. 24, 10861092. 